\title{
Ectopic Spleen Mimicking Kidney Activity Post-Nephrectomy
}

\author{
Hong Yun Ma, Raphaella Da Silva, Muhammad Shah, Leonard M. Freeman* \\ Division of Nuclear Medicine, Department of Radiology, Montefiore Medical Center and the Albert Einstein \\ College of Medicine, New York, USA \\ Email: "Ifreeman@montefiore.org
}

Received 3 December 2013; revised 3 January 2014; accepted 10 January 2014

Copyright $@ 2014$ by authors and Scientific Research Publishing Inc.

This work is licensed under the Creative Commons Attribution International License (CC BY). http://creativecommons.org/licenses/by/4.0/

(c) $\underset{\mathrm{EY}}{\mathrm{Br}}$ Open Access

\begin{abstract}
Ectopic spleen may simulate kidney activity on renal scintigraphic imaging. Accurate diagnosis requires correlation with the patient's history and anatomic imaging studies. We report a case where the spleen migrated to the left renal fossa and mimicked the left kidney after a left nephrectomy.
\end{abstract}

\section{Keywords}

Ectopic Spleen; Stimulate; Kidney Activity; Nephrectomy

\section{Introduction}

Ectopic spleen occurs when the spleen migrates from its fixed location in the left upper quadrant to an abnormal position. Developmental failures of the splenic ligaments, especially the gastrosplenic and splenorenal ligaments, which secure the spleen in its normal position, can result in a long splenic mesentery and an abnormally mobile spleen. In most of these situations, the ectopic spleen does not have clinical significance. However, when the ectopic spleen mimics variant and unexpected situations, e.g., in the scrotum [1] or pancreatic tail [2], it may significantly compromise clinical diagnosis. Here, we report a case where ectopic spleen simulates kidney activity on a renal scintigraphic study.

\section{Case Report}

A 46-year-old man presented with recurrent urinary tract infection [3] [4]. Patient had a left radiacal nephrectomy several years earlier for a renal cell carcinoma. Renal dynamic flow images (Figure 1) showed prompt aortic

\footnotetext{
${ }^{*}$ Corresponding author.
} 
activity, good right kiney blood flow and radiotracer activity in the left renal fossa; appearing to be the left kidney [5]-[8]. Subsequent follow through functional images demonstrated (Figure 2) normal right kidney uptake and fair transit of radiotracer into the collecting system. After 24 minutes, there were significant amount of radiotracer retention in the right kidney, consistent with significant right urinary tract obstruction. The factitious left kidney demonstrated fair uptake, but no evidence of transit or excretion. After the first 6 - 8 minutes, activity disappears from the left renal fossa without the progressive excretion expected from a normal kidney. After 24 minutes, there was only faint radiotracer activity noted in the left renal fossa [9] [10]. Axial CT images (Figure 3) demonstrated the left renal fossa was occupied by the migrated spleen (arrow). Patient was treated with right ureteral stent placement and repeated renal scan demonstrated the resolved right renal obstruction.

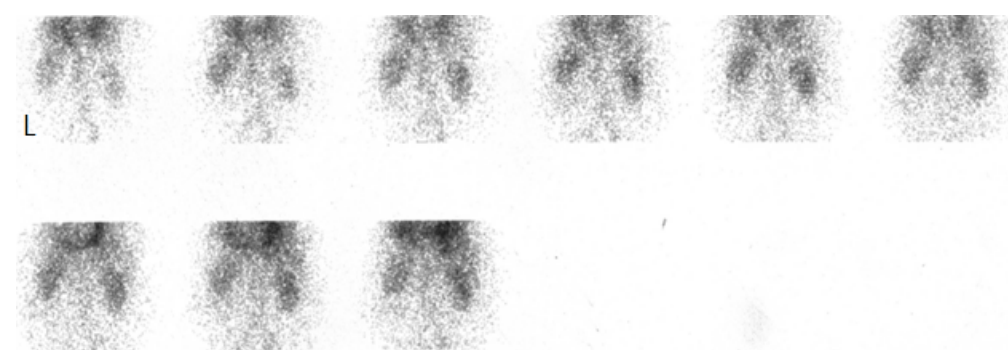

Figure 1. Renal dynamic flow images.
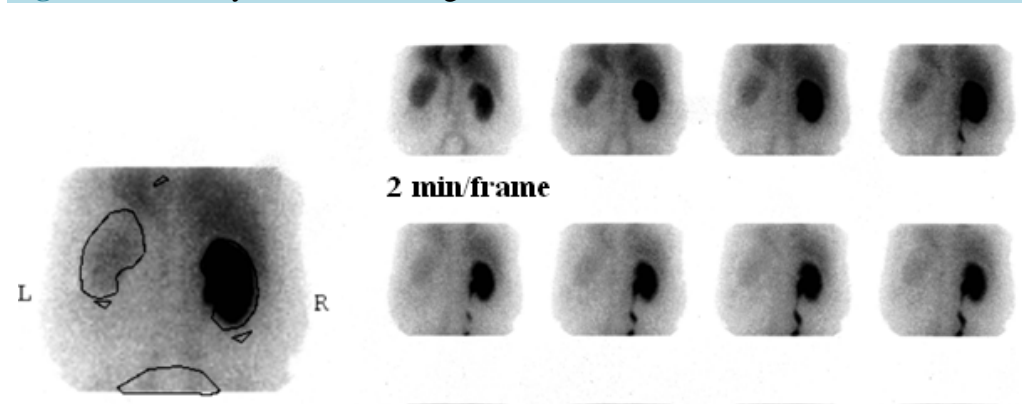

\section{2 min/frame}

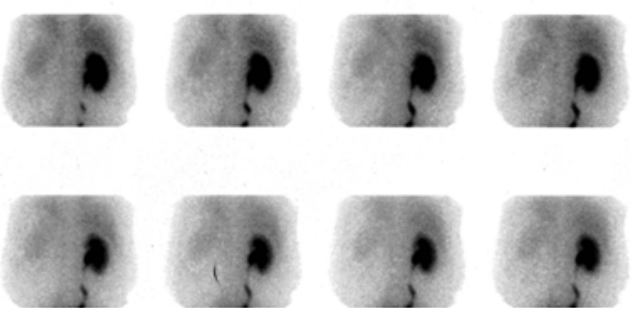

Figure 2. Renal functional images.

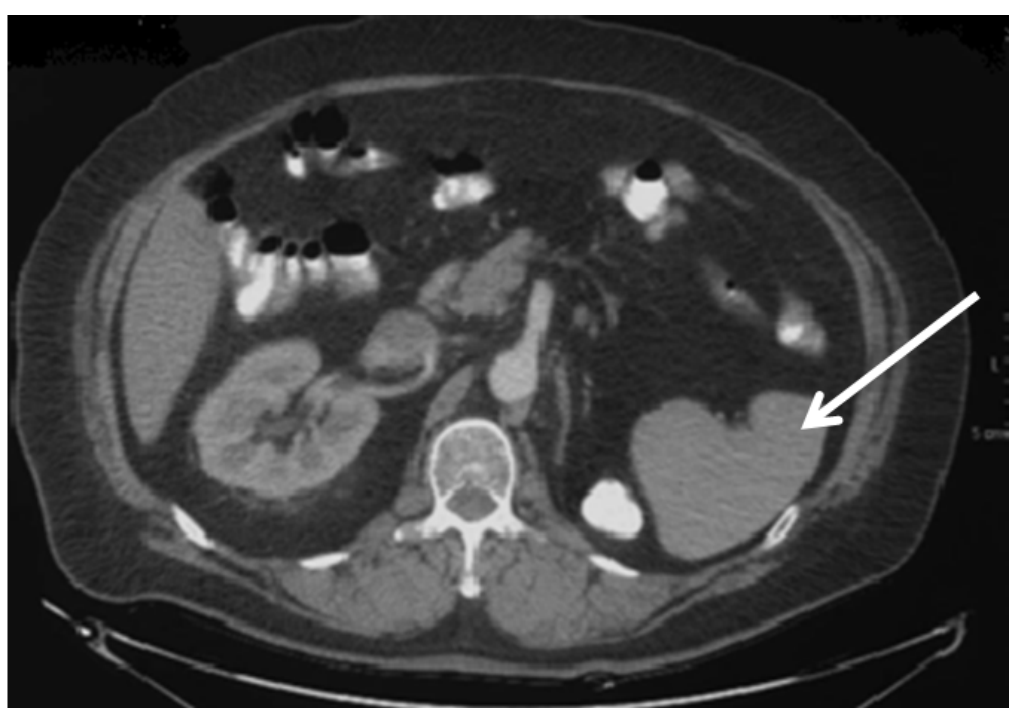

Figure 3. CT image showed left kidney is absent. The left renal fossa was occupied by the migrated spleen (arrow). 


\section{Discussion}

In this case, the spleen mimics not only the location and configuration of the left kidney, but also the perfusion. It is essential for Radiologists and Nuclear Medicine physicians to recognize numerous congenital variants of the spleen in order to avoid pitfalls and give correct interpretations. An ectopic spleen may be incidentally detected as an abdominal or pelvic mass, for example, Lask [7] et al. reported splenic tissue simulating a renal mass and Servadio [8] et al. reported splenic tissue mimic renal and adrenal tumor. The absence of the spleen in its normal position on CT images allows one to suspect an ectopic spleen and avoid incorrect diagnoses. However, the ectopic splenic tissue can be easily confirmed with Technitium $99^{\mathrm{m}}$ labeled sulfur colloid or Technitium $99^{\mathrm{m}}$ labeled heated denature red blood cell scans.

\section{Conclusion}

Ectopic spleen is an uncommon phenomenon occurring in about $0.5 \%$ of the population. It is important for the physician interpreting imaging studies to recognize its possible existence. A careful history and correlation with other imaging studies will help one to avoid this pitfall.

\section{References}

[1] Emmett, J.M. and Dreyfuss, M.L. (1943) Accessory Spleen in the Scrotum. Annals of Surgery, 117, 754-759. http://dx.doi.org/10.1097/00000658-194305000-00013

[2] Kawamoto, S., Johnson, P.T., Hall, H., Cameron, J.L., Hruban, R.H. and Fishman, E.K. (2012) Intrapancreatic Accessory Spleen: CT Appearance and Differential Diagnosis. Abdominal Imaging, 37, 812-827. http://dx.doi.org/10.1007/s00261-011-9830-X

[3] Kobayashi, Y., Usui, Y., Shima, M., et al. (2006) Evaluation of Renal Function after Laparoscopic Partial Nephrectomy with Renal Scintigraphy Using ${ }^{99 m}$ technetium-Mercaptoacetyltriglycine. International Journal of Urology, 13, 1371-1374. http://dx.doi.org/10.1111/j.1442-2042.2006.01579.X

[4] Inoue, Y., Kurimoto, S., Kameyama, S., et al. (2004) Prolonged Renal Parenchymal Retention of 99mTc Mercaptoacetyltriglycine after Nephron-Sparing Surgery. Nuclear Medicine Communications, 25, 509-513. http://dx.doi.org/10.1097/00006231-200405000-00013

[5] Onuki, T., Terao, H., Muraoka, K., et al. (2008) Splenosis Mimicking Local Recurrence after Radical Nephrectomy: A Report of Two Cases. Hinyokika Kiyo, 54, 353-356.

[6] Froehner, M., Leike, S., Manseck, A., et al. (1998) Splenunculus Mimicking Late Local Recurrence of Renal Cell Carcinoma. Scandinavian Journal of Urology and Nephrology, 32, 418-419. http://dx.doi.org/10.1080/003655998750015232

[7] Lask, D., Abarbanel, J., Rechnic, Y., et al. (1995) Ectopic Splenic Tissue Simulating a Renal Mass. Journal of Urology, 153, 1610-1611. http://dx.doi.org/10.1016/S0022-5347(01)67475-5

[8] Servadio, Y., Leibovitch, I., Apter, S., et al. (1994) Symptomatic Heterotopic Splenic Tissue in the Left Renal Fossa. European Urology, 25, 174-176.

[9] Liu, P. and Daneman, A. (1985) Unusual Position of the Spleen-A Report of Two Patients. Journal of the Canadian Association Radiologists, 36, 163-165.

[10] Forino, M., Davis, G.L. and Zins, J.H. (1993) Renal Splenic Heterotopia, a Rare Mimic of Renal Neoplasia: Case Report of Imaging and Fine-Needle Aspiration Biopsy. Diagnostic Cytopathology, 9, 565-569.

http://dx.doi.org/10.1002/dc.2840090520 